\title{
Delivering Knowledge Across Boundaries: A Case Study of Bankco's Offshoring Projects
}

\author{
Yuanyue Feng \\ Department of Information \\ Systems \\ School of Computing \\ National University of Singa- \\ pore, 117418 \\ yuanyuef@comp.nus.edu.sg
}

\author{
Hua Ye \\ Department of Information \\ Systems \\ School of Computing \\ National University of Singa- \\ pore, 117418 \\ yehua@comp.nus.edu.sg
}

\author{
Shan L. Pan \\ Department of Information \\ Systems \\ School of Computing \\ National University of Singa- \\ pore, 117418 \\ pansl@comp.nus.edu.sg
}

\begin{abstract}
Although prior empirical studies have repeatedly suggested that knowledge sharing between offshore clients and vendors is critical for the success of offshoring relationships, much less is known about the actual processes of knowledge delivery across organizational knowledge boundaries in these offshoring projects. To fill the research gap and enrich the academic literature, we propose a process framework to demonstrate the actual processes in which knowledge is delivered across boundaries between vendors and clients in the offshoring arrangements. By combining the framework of knowledge boundary and theory of absorptive capacity to analyse the case of BankCo's offshoring project, the stages are identified, through which various types of knowledge are sequentially delivered from clients to vendors by several processes in each stage. In particular, our study reveals that a strategic shift from total global offshoring project to global distributed teamwork renders BankCo an opportunity to overcome the hindrance of pragmatic boundary and insufficient absorptive capacity of the offshoring vendors.
\end{abstract}

Keywords: Knowledge boundary, Absorptive capacity, Knowledge delivery, Case study

\footnotetext{
* The three authors have equal contributions for this paper
} 
Delivering Knowledge Across Boundaries: A Case Study of Bankco's Offshoring Projects / Feng et al.

\section{Introduction}

With a considerable growth of market revenue from U.S. \$49 billion in 2005 (Everest Research Institute, 2009) to over U.S. $\$ 90$ billion in 2010 (Global Services Media, 2010), and is expected to exceed U.S. 300 billion in 2015 (Sri Lanka's National Newspapers, 2011), offshoring has been considered as an attractive and cost effective strategy for organizations to profit in nowadays turbulent global market. Albeit its significance and benefits are repeatedly highlighted, organizations adopting this strategy have thus far experienced low success rates. For example, a Gartner survey revealed a 50\% failure rate for offshoring initiatives (Aron and Singh, 2005). One of the key causes for the failures of offshoring projects falls into excessive knowledge transferring costs incurred between onsite teams and offshore teams (Carmel and Agarwal, 2002). The quality and continuity of client's services during the knowledge delivery process from onshore clients to offshore vendors posit challenges for both parties and are vulnerable to cost escalation (Chua and Pan, 2008; Von Krogh et al., 2000). This challenge of knowledge delivery can be attributed to the tacit nature (Von Krogh et al., 2000) and path-dependent nature of knowledge itself (Chua and Pan, 2008). Delivering the high level of clientspecific knowledge about their idiosyncratic business processes generates extra costs for offshoring project (Dibbern et al., 2008). In order to reduce the excessive knowledge delivering costs and minimize the disturbance of offshored service continuity, it is necessary to understand and facilitate the knowledge delivery in these offshoring projects. Thus it is imperative to explore how the knowledge can be effectively delivered from clients to vendors in the offshoring context.

Existing literature on offshoring has examined the success of knowledge delivery from both client's perspective (e.g., Ko et al., 2005; Willcocks et al., 2004) and vendor's perspective (e.g., Dibbern et al., 2008; Li et al., 2010; Modi and Mabert, 2007; Park et al., 2011; Thatcher et al., 2011; Williams, 2011). However, the emphasis of these researches has been primarily on deducting causal models which explore and examine antecedents for efficient knowledge delivery, rather than a close inspection of the actual delivery processes. The delivery processes change with the level of novelty, specialization, and dependence of knowledge (Carlile, 2002) and require various types of knowledge delivery mechanisms. Thus, a detailed investigation of the actual processes of knowledge delivery and their respective knowledge delivery mechanisms is needed to enrich our understanding of effective knowledge delivery.

Apart from the urgent need for a specification of actual delivery processes and mechanisms, previous literature on knowledge delivery has also discovered that organizations' heterogeneous capabilities, such as absorptive capacity, can influence their abilities and approaches to take advantage of external knowledge (Cohen and Levinthal, 1989; Ko et al., 2005). Some other studies have emphasized the critical role of management in knowledge sharing (Pan and Scarbrough, 1999). Applying this logic to offshoring projects, we believe that the efficiency of various types of knowledge delivery mechanisms in each delivery process may hinge on vendors' absorptive capacity. The notion of absorptive capacity can explain the efficiency of knowledge delivery in the offshoring projects above the types of delivery mechanisms and delivery stages.

With the motivations stated above, we propose a process framework by integrating Carlile (2002)'s framework of knowledge boundary with theory of absorptive capacity (Cohen and Levinthal, 1990). We separate the actual knowledge delivery lifecycle of a multinational bank's offshoring project into stages and delineate how different types of knowledge are delivered across boundaries to vendors. In particular, we investigate the underlying reasons behind the difficulty of knowledge delivery in this offshoring project. We reach the conclusion that the knowledge boundary framework can only suggest which types of knowledge are delivered and must be complemented with absorptive capacity theory, 
Delivering Knowledge Across Boundaries: A Case Study of Bankco's Offshoring Projects / Feng et al.

which explains how efficiently knowledge of a specific kind can be delivered.

\section{Literature Review}

Knowledge has long been recognized as a valuable resource for organizational sustainability and growth, especially for organizations competing in uncertain environments (Miller and Shamsie, 1996). According to the knowledge-based view of the firm, knowledge is the foundation of an organization's competitive advantage (Grant, 1996) and, ultimately, the primary driver of an organization's value (Teece, 2000). However, some strategic transfers and migrations of it (e.g. joint venture) are usually impeded by the tacit nature of knowledge (Von Krogh et al., 2000), and its stickiness (Suzlanski, 1996). Knowledge stickiness makes it laborious for organizations to absorb it from their partners and appropriate it in their own innovation processes (Carlile, 2002). This barrier for efficient knowledge delivery has been denoted as knowledge boundary by Carlile (2002, 2004), which would incur great efforts and costs for organizations sharing their knowledge with each other.

\section{Knowledge Boundary Framework}

Knowledge boundary was derived from the problem solving and knowledge creation across functions (Brown and Duguid, 2001). The framework of knowledge boundary is developed by Carlile $(2002,2004)$, and is further reconfirmed and extended by Ferlie et al (2005). The basic argument of this framework is that knowledge within a function actually hinders problem solving across functions because knowledge is localized, embedded and invested in practice (Carlile, 2002) and also in professionals (Ferlie et al., 2005). This specialization of knowledge in practice, and social and cognitive boundaries (Ferlie et al., 2005) make it especially difficult to work across functional boundaries and to accommodate the knowledge developed in another practice.

According to Carlile's framework, knowledge differs from each other in terms of degrees of novelty, specialization and dependence (Car- lile, 2004). Novelty denotes how novel the new demands and customer requirements organizations face in their operating environments (Calile and Rebentisch, 2003). Specialization means the differences in type and amount of knowledge which consume great efforts to adequately share and assess each other's knowledge (Carlile, 2002). Dependence refers to a condition where two entities must take each other into account if they are to meet their goals (Carlile, 2002). As the novelty increases, the specialization and dependence will also increase (Brown and Duguid, 2001).

Different levels of novelty, specialization, and dependence will create different knowledge boundaries (i.e., syntactic, semantic and pragmatic boundary) which require different boundary objects and approaches to overcome (Carlile, 2004). For the basic level, when the knowledge is low in novelty, specialization and dependence, a common lexicon (boundary object) which is created by storage and retrieval of knowledge (Davenport and Prusak, 1998) can facilitate the explicit knowledge transfer across the syntactic boundary. In other words, actors in knowledge delivery require a common dictionary to transfer explicit knowledge across syntactic boundary.

For the intermediate level, when the novelty, specialization and dependence of knowledge arise, a common meaning referring to a set of terms and habits shared by both parties of knowledge delivery is required to ensure accurate translation and interpretation of the knowledge across the semantic boundary. By paying attention to the challenges of conveyed meaning and the possible different interpretations by individuals, this translating approach recognizes the individual and contextual aspects in knowledge delivery, and pays particular attention to the tacit nature of knowledge (Polanyi, 1966). In a nut shell, when novelty of knowledge arises, a common understanding is a must for parties to grasp the actual meaning of knowledge delivered from counterparts and to avoid misinterpretation. 
Delivering Knowledge Across Boundaries: A Case Study of Bankco's Offshoring Projects / Feng et al.

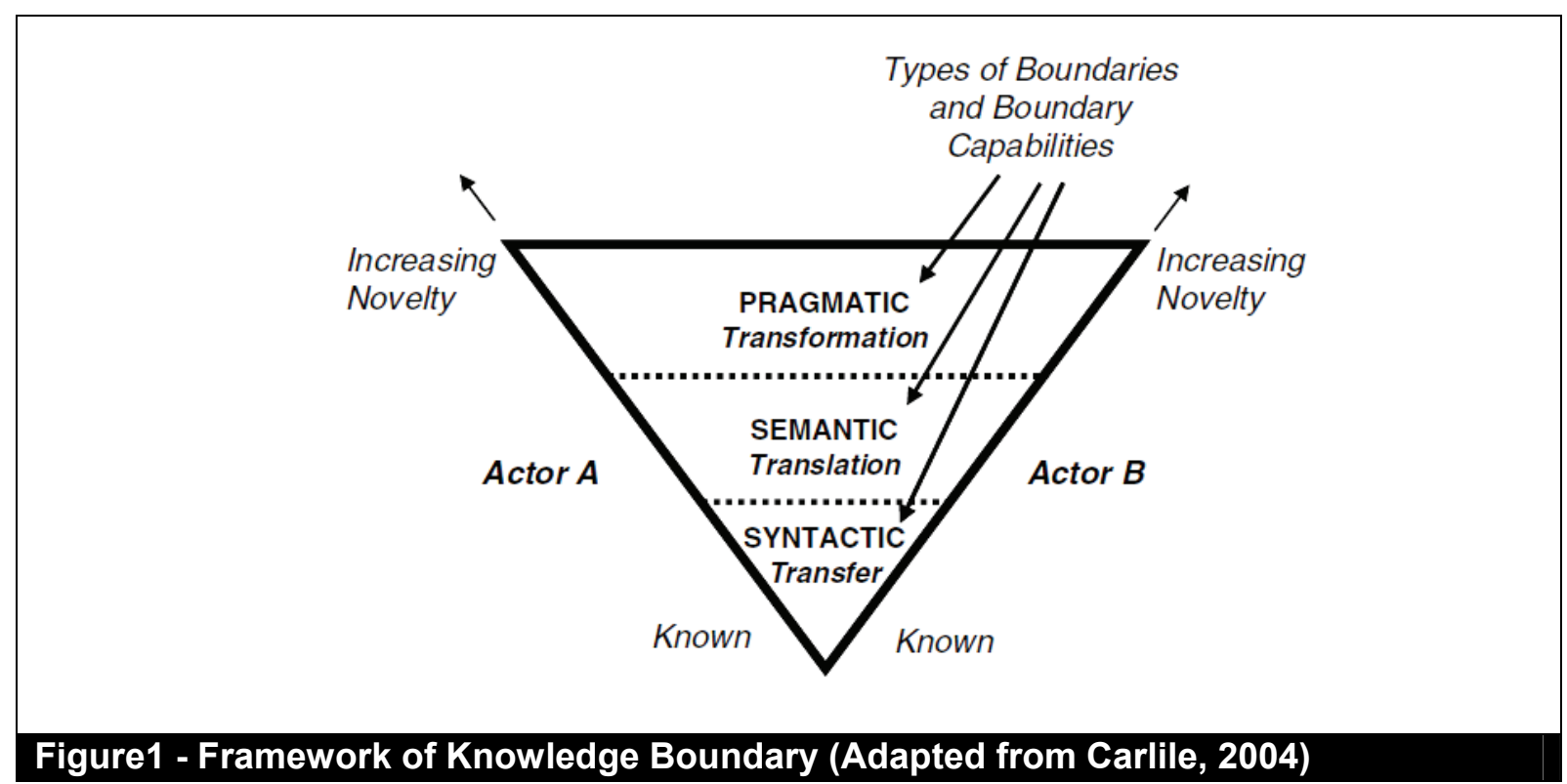

The last level is the pragmatic level, in which a common interest has to be achieved when participants negotiate with each other on the scope, consequences and conflict resolutions of knowledge delivery. Despite the previous two processes, in some cases of high knowledge novelty, specialization and dependence, conflicts among stakeholders between organizations, or between knowledge management practices and other practices in a single organization, will surface when their interests contradict with each other (Tan et al., 2005; Oshri et al., 2006). To solve the conflicts and preserve the fruits of knowledge delivery, there must be an overall process for transforming existing knowledge to deal with the negative consequences that arise. This transforming approach refers to a process of altering current knowledge, creating new knowledge, and validating it within each function and collectively across functions (Carlile, 2002). It highlights the importance of understanding the consequences that exist between things that are different and dependent on each other. To sum up, common lexicon and meaning cannot guarantee the success of knowledge delivery when knowledge is highly novel, specific and path-dependent; knowledge has to be transformed to reconcile and coordinate the interests of different participants.
The whole framework of knowledge boundary is presented in figure 1 (adapted from Carlile (2004)). The whole process of knowledge delivery between two parties consists of three sub-processes: transfer, translation and transformation.

\section{Theory of Absorptive Capacity}

Absorptive capacity, which was coined by Cohen and Levinthal (1990), has been frequently used by researchers to interpret the organizational and individual's learning (Lane et al., 2001), knowledge sharing (Cummings, 2004) and innovation behaviors (Gupta and Govindarajan, 2000). An organization's absorptive capacity is defined as the ability of the firm to recognize the value of new, external information, assimilate it, and apply it to commercial ends (Cohen and Levinthal, 1990). Absorptive capacity, developed and strengthened by continuous funding of and engaging in R\&D over time (Cohen and Levinthal, 1990), enables a firm to screen, evaluate, and exploit new knowledge that originates from beyond its boundaries (Mowery, 1983; Helfat, 1994). It has been argued that absorptive capacity of a firm is critical to its knowledge sharing and success of relationships with external partners (Lee, 2001). While engaging in relationships with external parties, organizations have to go through three processes (i.e. acquisition, assimilation 
Delivering Knowledge Across Boundaries: A Case Study of Bankco's Offshoring Projects / Feng et al.

and application) in order to absorb and benefit from the external knowledge.

Absorptive capacity is nurtured in a prolonged process of investment and knowledge accumulation. As suggested by Cohen and Levinthal (1990), organizational units with a high level of absorptive capacity invest heavily in their internal development (e.g., R\&D and personnel training) and thus possess strong capability to utilize external knowledge to produce innovations. When the absorptive capacity is low, organizational units will be greatly paralyzed and cannot exchange knowledge and learn from each other. For example, in a study of 122 best-practice transfers in eight companies, Szulanski (1996) found that lack of absorptive capacity marked a major barrier to internal knowledge transfer within organizations. Apart from this, the absorptive capacity of a firm may also stem from its openness towards knowledge sharing such as the strategic alliance and participation in collaboration (Caloghirou et al., 2004). Furthermore, it has been also noted that a firm's absorptive capacity is largely a function of its level of prior related knowledge (Cohen and Levinthal, 1990). And the absorptive capacity has been found to facilitate knowledge transfer and inter-organizational learning, thereby ensuring value creation in offshore IT sourcing relationships (Gottschalk and SolliSather, 2007).

\section{Complementarity of Knowledge Boundary Framework and Theory of Absorptive Capacity}

Scholars applying the framework of knowledge boundary have primarily focused on the three types of knowledge boundaries and studied the sources of the knowledge boundaries, such as differences in country contexts and professional and industry practices (Levina and Vaast, 2008). Other researchers adopted this framework to interorganizational relationships and interpreted the behaviours of crossing boundaries, such as sense making, sense demanding and sense breaking (Vlaar et al., 2008). However, the knowledge boundary framework only explains the types of knowledge which can be delivered across boundaries, but fails to account for the efficiency of knowledge delivery. The efficiency of knowledge delivery can be explained by the absorptive capacity theory. According to absorptive capacity theory, the efficiency of knowledge delivery is influenced by the team's capabilities of knowledge acquisition, assimilation, and application. Empirical studies applying absorptive capacity theory to cross-boundary knowledge delivery have justified the critical role of receiver's absorptive capacity for the knowledge deliver (Galbraith, 1990; Hamel, 1991). For instance, Lane et al. (2001) have empirically found that the relative absorptive capacity of international joint ventures (IJV) with their foreign parents enables them to more efficiently understand, assimilate, and apply new knowledge held by their parents, thereby enhancing their performance. Similarly, based on a sample of 2265 Spanish firms, Escribano et al. (2009) found that firms with higher level of absorptive capacity could manage external knowledge flows more efficiently, and stimulate innovative outcomes. Furthermore, scholars applying the notion of absorptive capacity to analyse organizational sourcing activities have empirically justified its catalysing effects on knowledge delivery (e.g., Chen and McQueen, 2010; Lee, 2001; Rothaermel and Alexandre, 2009). From the above evidence, it is not hard to see that the absorptive capacity theory could explain the efficiency of knowledge delivery in addition to the types of knowledge offered by the knowledge boundary framework. However, prior literature solely focused on either boundary framework or absorptive capacity theory when they studied knowledge delivery phenomenon, thus ignoring the merits of combining these two theoretical lenses together.

As the offshore sourcing activities involve various types of knowledge being intensively delivered through sequential stages from clients to vendors, we believe that integrating the knowledge boundary framework and absorptive capacity theory is elucidative in explaining how the knowledge is delivered across the intellectual boundaries between vendors 
Delivering Knowledge Across Boundaries: A Case Study of Bankco's Offshoring Projects / Feng et al.

and clients and why the total offshore sourcing project ends up with a global teamwork.

\section{Methodology}

Given that the targeting phenomenon of our research, which is the underlying process through which knowledge is effectively delivered in offshoring arrangements, is a newlyemerged and highly multi-faceted complex practice, we adopted a structured-pragmaticsituational approach (SPS approach) and went through eight steps to inductively derive our process framework in our exploratory case study (Pan and Tan, 2011).

As our research topic requires contextually rich descriptions with emphasis on language and social relationships rather than numbers and variables, the qualitative data collection technique was preferred (Yin, 1994). Based on the methodology we have chosen, BankCo, a multinational banking organization, is selected and accessed as the single research site as its IS functions are sent offshore for software development and maintenance.

Data collection was started in December 2004, when the authors spent two months in the field. The case study was carried out using both formal and informal interviews. Project and programme documentation, published sources, follow-up e-mails and telephone calls were also used as other sources of information (Yin, 1994). Data collection started with short informal sessions ranging from 10 to 20 minutes each with a few selected managers so as to identify the teams that would be formally interviewed. As the programme stretched over four years since 2001, teams had to be carefully selected such that they were the latest teams that had just completed the transition projects, so as to avoid threats to internal validity due to the maturation of the interviewees (Cook and Campbell, 1976). Two teams were selected for this study. The Cards business application team was selected as it represents a very large and complex application which had about 70 supporting members with onshore concentration of $90 \%$ in Hong Kong and Singapore, and $10 \%$ in Malaysia (offshore). The other selected team was the CRM (Customer Relationship Management) team which involved a smaller team of 20 people supporting many small CRM applications, with greater dominance in Hong Kong and Malaysia (offshore) compared to Singapore. In both instances, completion of the whole migration process was in the fourth quarter of 2004.

Once the teams were identified, formal interviews were conducted at different levels of the organization (See Table 1). A total of 16 formal interviews were conducted. Data collection and analysis techniques were informed by the principles of grounded theory (Glaser and Strauss, 1967). First, data collection was intertwined with data analysis. The interviewers took analytical notes about what was learned after each interview. Based on these notes, interview protocol was revised and new questions were added to see whether the opinion of the next interviewee could support, further develop, or reject the emerging patterns. Finally, data collection process completed when it reached a state of theoretical saturation with respect to a particular issue (Levina and Vaast, 2008). At the organization level, the program management team (three interviewees) was interviewed to get an understanding of the objectives, procedures and outcomes of the whole program. At the group level, team-specific senior managers and project managers (six interviewees) were interviewed on the planning and execution of the transition project. Finally, at the individual level, system analysts and programmers (seven interviewees) were interviewed on the actual execution of the knowledge transfer. Interviewees comprised of a mix of onshore and offshore staffs from the two selected teams. All interviews were recorded (with the exception of 2 which were specifically requested not to) and transcribed. Duration of the interviews ranged between 30 minutes and 90 minutes. The interviewees typically started with describing the role that they played in the transition, followed by expressing their experience, feelings, and concepts of success about the transition processes. 
Delivering Knowledge Across Boundaries: A Case Study of Bankco's Offshoring Projects / Feng et al.

Table 1 - List of Interviewees

\begin{tabular}{|l|l|l|}
\hline Interviewee Type & \multicolumn{2}{l|}{ No. of Interviewees } \\
\hline Program management & 1 & \\
\hline Program director & 1 & \multicolumn{2}{l|}{} \\
Transition manager & 1 & Offshore \\
Quality manager & Onshore & N/A \\
\hline Business application software teams & 1 & 2 \\
\hline Senior manager-in-charge & 3 & 3 \\
Project management & 4 & \\
System analysts and programmers & 16 & \\
\hline Total &
\end{tabular}

Data analysis of the case started by breaking down the events in the chronological order of the knowledge transfer, translate and transform. Care was taken to ensure that equal attention was given to all stages (Yin, 1994). Transcripts of interviews were scrutinized for patterns and recurring themes. For example, one of the themes that emerged was that, depending on the types of knowledge that was being transferred, translated or transformed, different boundary spanning approaches were adopted. An iterative process of comparing empirical evidence with existing literature gave rise to possible theoretical conceptualizations. The data were further analysed using these theoretical concepts. Triangulation was done within a team, among onshore staffs and offshore staffs at different project management and system analyst levels.

\section{Case Description and Analysis Organizational Background}

BankCo is a multinational bank with 30,000 staffs located in 50 countries. It reaped an annual revenue of over US\$ 5.37 billion in 2004. It offers a wide range of banking services including consumer banking, priority banking, private banking, SME banking, wholesale banking, and Saadiq Islamic banking. All the workers of BankCo in various countries with different cultural backgrounds share all kinds of knowledge with their colleagues every day, such as sharing business and technical knowledge with peers in the same location or cross-national locations. Before 2001, the onshore working sites of BankCo mainly located in United Kingdom, Hong Kong and Singapore. In 2001, after a review of its global technology business development and support organization, BankCo decided to progressively relocate its working sites to offshore lower-cost locations, which are India and Malaysia. The move of work from onshore sites to offshore locations was launched due to three challenges BankCo faced in their global operations. First, BankCo tried to lower the cost of resources through offshoring so as to balance the production economics against the cost of production (Cheon et al., 1995). Second, BankCo was urged to reduce the risk of shortage of technology resource in its onshore locations, which was plaguing the technology industry in 2001. BankCo was indeed dependent on elements in the external environment munificence, which forced the company to look offshore to alleviate this problem. Third, BankCo also aimed at improving productivity and quality through centralization in the two offshore locations.

However, some of the business of onshore locations had been retained in-house and the offshore vendors' human resources only amounted to about $25 \%$ of the total personnel of BankCo. This multi-sourcing strategy was due to two reasons. Firstly, some of the knowledge of onshore work was considered 
Delivering Knowledge Across Boundaries: A Case Study of Bankco's Offshoring Projects / Feng et al.

highly strategically sensitive or very hard to learn by offshore workers. Such kind of sticky knowledge deeply embedded in onshore workers' tacit behaviors and cannot be easily and fully delivered to the offshore teams. Thus such work had to be retained in-house. Secondly, the profit requirement of vendors makes it more cost effective for BankCo to have its own in-house resource. BankCo estimated that it could break even on the cost of investment in its own offshore development centres within 1.8 to 2 years.

The relationship between BankCo's onshore and offshore sites is actually intraorganizational. The onshore and offshore sites both are within BankCo's organizational boundary, but they possessed different knowledge backgrounds that created knowledge boundaries between them. The original goal of the offshoring project is to deliver knowledge across these boundaries from onshore sites to offshore sites so as to allow the offshore sites to fully and independently carry on some of the onshore tasks.

For the knowledge delivery to offshore sites, BankCo encountered three main challenges. First, BankCo must ensure a smooth and complete transition of onshore tasks to offshore. Second, BankCo must keep key personnel with vital business and application knowledge in the company until the knowledge delivery was done. Third, BankCo must complete the whole transition process within a relatively tight schedule. Each team's transition was given between six to nine months, with a few teams involving complex business applications given no more than one year to complete.

Thus, to enact and enhance the knowledge delivery from onshore sites to offshore sites, BankCo sequentially went through three phases in which it conducted different processes and utilized different mechanisms to facilitate the delivery of knowledge across the knowledge boundaries between onshore and offshore teams. These three phases were labelled as: transfer, translation and transformation. The specific information about the three processes will be presented in the case analysis section.

Through the above three phases, BankCo had successfully delivered most of its knowledge to its offshore vendors. However, it was suddenly realized that although the technological knowledge of the system analysts and programmers can be wholly delivered to offshore locations, some of the more specific business knowledge and domain knowledge of senior analysts and project managers could not be easily learnt and absorbed by offshore staffs. In order to quickly utilize the intelligence of offshore members and make sure they shoulder their responsibilities, BankCo temporarily changed its total offshoring strategy into global teamwork in which senior members of onshore teams cooperated with offshore workers. The global teamwork had been performing effectively in aligning different interests between BankCo and its vendors as well as facilitating the delivery of business knowledge. Although the offshoring project was officially completed at the end of 2004, the replacement of onshore staffs with offshore staffs was still going on even though the scale was smaller.

\section{Case Analysis}

\section{Transfer: Common Lexicon Creation and Knowledge Acquisition}

The knowledge delivery lifecycle starts with explicit knowledge transfer phase (See the S1a: Transfer and S1b: Knowledge Acquisition in Figure 2).

Firstly, project initiation was done on both the onshore and offshore managerial teams. Offshore project managers and onshore project managers have a different set of work cut out for them. For the offshore project managers, one challenge for them is to find as many suitably qualified members to quickly build up their teams. However, finding qualified staffs was not easy as pointed out by an offshore project manager in Malaysia. The sudden ramp-up by 2.5 times the current number of staff within two months was extremely tough to accomplish. As recounted by an offshore project manager: 
Delivering Knowledge Across Boundaries: A Case Study of Bankco's Offshoring Projects / Feng et al.

\begin{abstract}
"They wanted 50 people! Where are we going to get these people? What kind of skills do we look for? What kind of composition - like how many analysts, how many project managers, how many developers? [With such a large requirement], we just went out there and grabbed everybody available in the market!"
\end{abstract}

This created a loss in the correct skill set that was found so as to match it to the required experience base. Due to the large number of recruits required, insufficient qualified staffs were found in a short time frame. Without pre-requisite experience, it was hard to transfer the knowledge to the recipients. As an onshore system analyst pointed out:

"... [if] the skill set doesn't match in the first place when you assign him to me for transition, I think that is potentially an issue. You can't just hire anybody and transfer the knowledge. It will never work that way because transition is not training [from scratch]."

From the onshore side, the Programme Management Office decided which teams to be sent offshore and the onshore and offshore teams' composition. They also planned the knowledge delivery schedule and created transition guide and training contents.

Besides the detailed transition guide, the program management office also provided the offshore teams with the explicit information of this project. After initiating the project by careful planning process, various kinds of onshore knowledge were pulled together to prepare for the later delivery process. Onshore project managers called for different workers in different onshore locations to prepare training materials in their own expertise fields and collected them together. As one onshore project manager mentioned:

"... If there were certain topics that we ourselves couldn't do because we were not familiar with it, we will bring in the people from Hong Kong or Singapore. We planned it such that when the person flew over [to the offshore location], they would take a few topics and do the training."

These collective explicit knowledge repositories which offshore teams were assumed to know in order to form a solid knowledge base were codified in the manuals documents and presentation slides. As recounted by an onshore project manager:

"Firstly we listed out what were the key areas that we had to cover. For example even in PSS [production support], there are a lot of procedures there for day or night PSS. So we have to document them down - what are all the steps. We than prepare the presentation materials. We will plan out the timetable for the training and the different topics to train. Besides the procedures for the day or night PSS or even software migration, because we do software migration, we also come up with guidelines, like developers guidelines when you code JCL or when you code programs, the standards that we follow, the naming conventions for programs and copy books. Then we move also into the $A \& D$ [analysis and design] training and include all the different functionalities that we need to train the people."

After the preparation of explicit knowledge, the detailed explicit knowledge was transferred to offshore members through face-toface, one-to-many presentations. These presentations aimed at imparting as much explicit business and technological knowledge to all the offshore members as possible.

The above processes including staff recruitment, project initiation, explicit knowledge centralization, explicit knowledge codification, and explicit knowledge impartation were used to establish a shared and stable syntax which ensured accurate communication between both teams. Through these processes, BankCo had created a common lexicon as a boundary object between onshore and offshore members and allowed offshore members to acquire explicit knowledge delivered across syntactic boundary. 
Delivering Knowledge Across Boundaries: A Case Study of Bankco's Offshoring Projects / Feng et al.

In order to evaluate the amount of explicit knowledge acquired by offshore members, oral and written quizzes were provided by onshore teams to check whether the offshore members had formed a general impression and sufficient grasp for the syntactic knowledge delivered in this phase. As said by an onshore project manager administering the quizzes:

\section{"After every session [presentation], there is a quiz - we prepare the quiz questions. The quiz questions mainly concentrate on providing the important things that we need them to know for that particular session. Then we will mark and grade them."}

However, the offshore staffs were not expected to understand all the material immediately. The intention in this phase was to provide them a broad overview of the key application knowledge concepts and features so that when they do encounter a particular topic in future delivery, they would be able to refer back to the materials and gain better understandings. As said by a trainer (programmer of onshore team):

'Honestly I don't think they would absorb $100 \%$, but I would expect that because we had the materials - we kept the hard copies in the server - one of these days if they do come across a topic in their projects, they would know where to dig up."

Some of the offshore staffs, although admitting that it was difficult for them to absorb all the knowledge being presented due to the huge quantity of information, still felt that they have absorbed sufficient and necessary explicit knowledge which makes them "aware" of and grasp the functionalities and features of the systems. As a system analyst from the offshore team recounted:

'The training was not a waste of time it was more of giving us the awareness. I would consider it more of an awareness training. I don't think that a person goes into a training room and becomes perfect. At least he is aware that we have this [functionality] and we have that [feature]."

\section{Translation: Common Meaning Creation and Knowledge Assimilation}

After delivering explicit knowledge across syntactic boundary, BankCo started to deliver more tacit knowledge in translation phase (See the S2a: Translate and S2b: Knowledge Assimilation in Figure 2). This type of knowledge was stickier but could provide

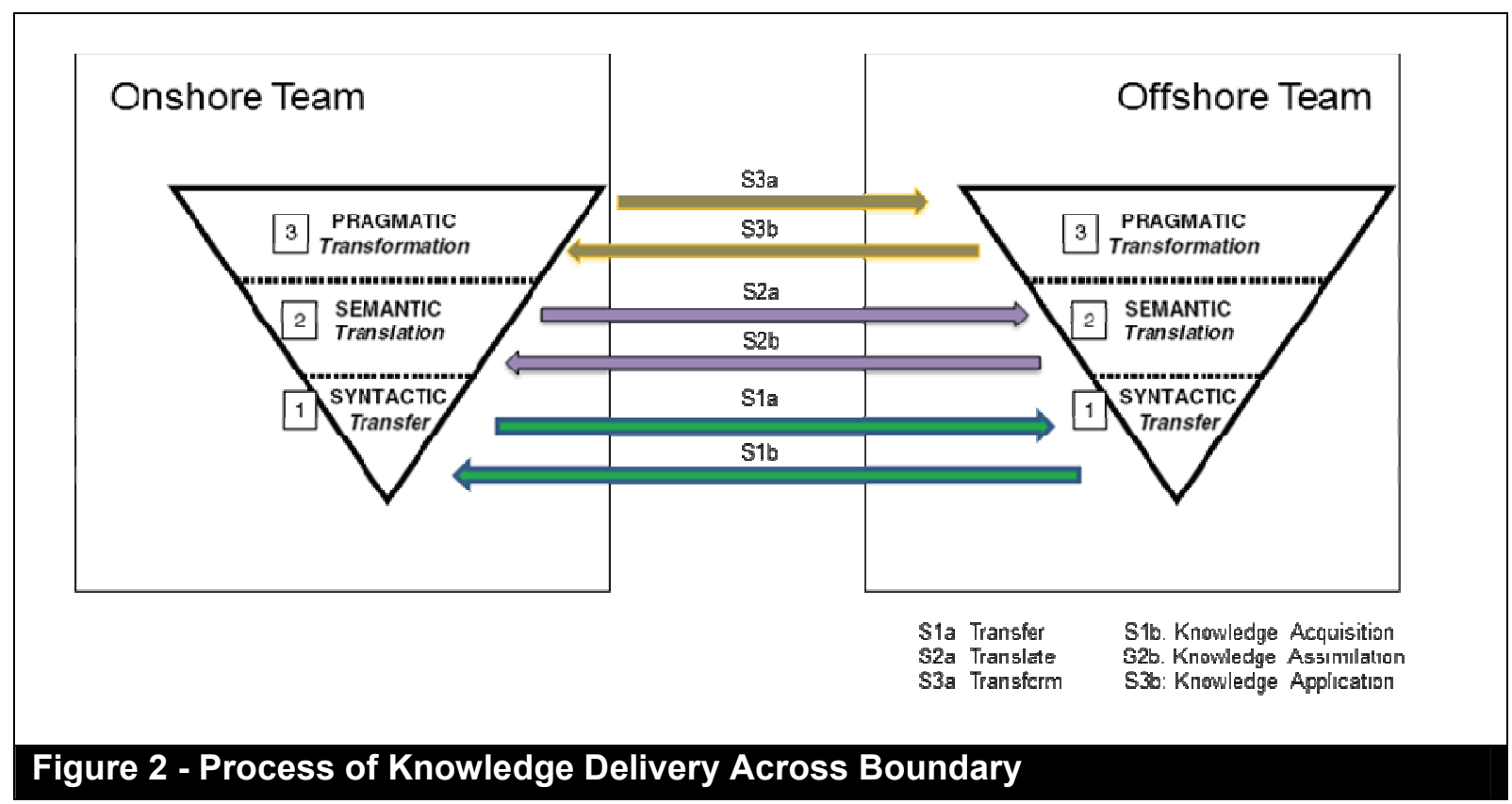


Delivering Knowledge Across Boundaries: A Case Study of Bankco's Offshoring Projects / Feng et al.

deeper understandings for the offshore members. Some application domain knowledge, which was supposed to be inherent in onshore staffs with banking experience, was very hard to be assimilated by offshore members. The interpretation and assimilation of this kind of knowledge were facilitated by several processes launched by onshore teams. The first process was the on-jobtraining (OJT) in which onshore team members flied to offshore sites and showed the offshore members how to do the work. A group of offshore staffs sat next to the onshore staffs and observed the methodology used to solve a problem, and noted the business parties that onshore staffs had to get in touch with to update the status. By participating in this kind of "live show" of dealing with the job, offshore staffs could gain a deeper understanding for the actual and domainspecific meaning of the technology and business knowledge they had learnt in previous transfer phase.

Another process onshore members had used is the playback sessions. In these sessions, the offshore team members presented the knowledge they have acquired and assimilated back to the onshore teams. The onshore members would make a trip to offshore location to check for the gaps in the knowledge and retrain the offshore teams on the areas that were lacking or unsatisfying. They would also observe whether the offshore teams had integrated their learning into the in-country processes correctly. While the on-job-training was more about the knowledge flows from senders to receivers, the Playback session ensured the offshore members interpreting the knowledge by a form of learn-by-doing and also the onshore members learning of new knowledge born in the offshore context. As an offshore technical manager recounted:

"[The onshore staff] came here to observe [to see how problems were solved], to see whether if there was anything done right or wrong. There is an activity called PlayBack session, where you present what you have learnt in terms of the PSS process and the onshore activity. There is also a functional lunch to share with him and another business person, so that they have a feeling whether we are on the right track."

The exchange and coordination of meanings of jobs between onshore members and offshore members was the main theme of these two activities. These processes were used to establish a shared and stable semantic understanding which ensured deep communication between both teams. Through these processes, BankCo had created a common meaning as a boundary object and allowed offshore members to assimilate tacit knowledge delivered across the semantic boundary.

The individual interview assessments and team reviews were used for the evaluation of assimilation progress of the offshore members. The amount and accuracy of assimilation of semantic knowledge were assessed. During the individual interview assessments, the offshore members were asked to describe in detail the key areas in a particular topic or problem. They were required to guess what questions they would receive and find out the answers by themselves. As an onshore project manager mentioned:

\begin{abstract}
"Before the test, we actually told them the topics that we were going to cover. They had to go and guess the questions. We had all the questions ready but different people would get different questions. We will pick-and-choose which questions we wanted to ask them. So there were two or three of them that didn't do so well. They had to go back and study again and then come for another test."
\end{abstract}

Through the on-job-training and playback sessions, offshore team members have assimilated much of the application domain knowledge necessary for them to interpret and understand the real meaning of the jobs. As an offshore programmer talked about his feelings for the on-job-training (OJT) in the individual interview assessment:

"After that (the presentations), OJT (onthe-job training) was more effective, 
Delivering Knowledge Across Boundaries: A Case Study of Bankco's Offshoring Projects / Feng et al.

whereby we had live situations and was understanding it better and getting things done more effectively."

\section{Transformation: Common Interest Crea- tion and Application}

Knowledge has to be transformed before it could be applied to real work (See the S3a: Transform and S3b: Knowledge Application in Figure 2). Although most of the current explicit as well as tacit knowledge had been substantially delivered to offshore teams, some knowledge which deals with the problems happened in the past was not likely to be experienced by offshore members only through the above phases. Support simulation was then used as a way of prototyping the past problems and solutions for the offshore members thereby enhancing their abilities to cope with all the possible problems encountered in their jobs. This kind of mechanism was created as an interest-free stimulation for innovation. As evidenced by the draft of our record:

"Not all technical issues could be experi-
enced on-the-job. Many technical prob-
lems that happened in the past were un-
likely to reoccur. However, they provided
a good way of testing the offshore
team's knowledge of the system and the
thought process on how to solve the
problem. In support simulation, the on-
shore staff selected past problem tickets
and got the offshore staff to work on
them. The offshore staff, through think-
ing out loud, walked through how they
would solve the problem."

Another challenge arising in this phase is a conflict between onshore and offshore project managers on the "sense of urgency". There was a common compliance by onshore project managers that the offshore staffs lacked the "sense of urgency" when solving problems in production support. Onshore project managers felt that offshore staffs were not working fast enough to solve high-severity problems which had high impacts on customers. Whereas offshore project managers felt that their staffs were moving as fast as they could. As one of the offshore project managers replied:

\begin{abstract}
"You can never get to emulate the urgency, that pressure in trying to get people to fix it. The onshore people say that this is supposed to be in the training material before someone goes into support. I say that that's telling a person: This is roughly Step 1, 2, 3, 4 - it's very textbook kind of stuff. But it doesn't tell me on the spot whether I am able to do it or not."
\end{abstract}

To reduce these negative conflicts, some onshore Quality Managers would audit the Team Transition Process and check whether the business users were satisfied. As described by a Quality Manager on the acceptance-into-production process:
"...how do we know that they are ready? We know it through interviewing people, by looking through that "Yes, you have done the on-the-job training, playback and all these, as per documented in the process documented." But whether the- se people have really transferred the knowledge, the document will not be able to tell you. So what we do is we would interview the people doing the transitioning by asking the managers: - "are you happy with it?" We also ask those who are at receiving end: "are you happy with it?" Finally, we will ask the Customer [business owner]: "are you happy with it?"'

Besides this, onshore and offshore project managers would jointly do a team readiness assessment. These two mechanisms can be seen as ways of negotiating the different interests among the different stakeholders. By applying the knowledge delivered to their work processes, offshore members performed the onshore work back to all the stakeholders and tried to meet their needs. Only when every stakeholder was satisfied with the performance of offshore team members can the onshore staffs be replaced by the satisfying offshore staffs. 
After the prototyping and interest negotiating processes, the interests of the onshore teams and offshore teams tended to be harmonious with each other. This established shared interest facilitated the knowledge delivering across the pragmatic boundary. However, some knowledge which was quite sticky was deeply rooted in the onshore organizational memory and practice, and was too hard to be delivered to offshore teams either due to great effort needed for delivery or high sensitiveness of the knowledge. Some onshore senior analysts and project managers were reluctant to share their whole business knowledge with offshore teams in fear of losing their competence and their positions. Also they were tired of teaching the offshore members the depth of knowledge required to do analysis and design. These subjective and objective hindering factors resulted in the low application opportunity for the offshore members, which in turn undermined the knowledge applying capability of the offshore members. Thus, some offshored jobs were not satisfactorily done due to the low applying capability of the offshore members. Eventually some of the more high-level onshore members were finally retained at the end of project. For example, a common assessment for compliance to local country banking regulations needed to be done for all business applications in multinational banks. However, the onshore senior project managers recruited onshore staffs from local banks that did not have any experience in the area of compliance. Therefore the knowledge on compliance was not delivered to offshore members in the training. The offshore members had no choice but to work with the senior analysts from the onshore teams to understand the compliance process better and apply their learning immediately on-the-job. As complained by an offshore system analyst:

"These guys (onshore staffs) come with their limited experience (on compliance) from their local bank and we were required to roll out compliance. We had so many issues not understanding the processes and trying to learning from specialists on the job."
Since some of the onshore members (especially those on senior level) were not replaced at the end of project, and the offshore members were not ready to take over the whole production process on their own, BankCo quickly realized that they had to change the total offshoring strategy into global teamwork. The personnel of the global teamwork were constituted by both senior managers or analysts from onshore teams and technicians (programmers) or system analysts from offshore teams. The change of strategy, which could be seen as a kind of strategic knowledge conversion, was due to the insufficient knowledge delivery across pragmatic boundary between onshore and offshore teams at the end of project. The insufficient knowledge delivery was in turn due to the insufficient common interest on the pragmatic boundary and unsatisfying application capability of the offshore members. Thus the strategy of global teamwork acted as a boundary object which temporarily enhanced the knowledge application on the pragmatic boundary and guaranteed the continuity of the service at the end of offshoring project. In the global teamwork strategy, both the onshore and offshore members reported to one global team manager, the manager would continue to negotiate the interests between onshore and offshore members, which acted as a boundary object for continuous delivering of knowledge. The global teamwork seemed to work very well, as observed by an offshore manager:

"I think what helped most was the reorganization where all of us reported into one common manager. The mindset is so different now."

\section{Discussion}

\section{Knowledge Delivery across Boundary}

From past literatures, we identified three types of boundary objects for enhancing knowledge delivery across three kinds of boundaries based on the framework of knowledge boundary and also discovered three capabilities by which offshore members absorb the knowledge flown from onshore 
Delivering Knowledge Across Boundaries: A Case Study of Bankco's Offshoring Projects / Feng et al.

teams (refer to Table 2). Next, we discuss how boundary objects are established and complemented or supported by offshore employees' absorptive capacities in facilitating seamless knowledge delivery.

\section{Transferring Across Syntactic Boundary}

The transferring of knowledge across syntactic boundary requires two preconditions: (1) creating a common lexicon between onshore and offshore teams, and (2) acquiring sufficient explicit knowledge from onshore teams by offshore teams. Based on the empirical evidence uncovered in BankCo's project, first, by staff recruitment, project initiation, explicit knowledge centralization, explicit knowledge codification and explicit knowledge impartation, the common lexicon between onshore teams and offshore teams had been created. Staff recruitment built up a qualified offshore expertise base to acquire the knowledge to be transfer from onshore teams. Project initiation created a consensus between both onshore and offshore teams on the detailed schedule and steps for the whole delivery process. Explicit knowledge centralization allowed the various kinds of knowledge distributed across onshore departments and locations to be aggregated into one point for delivery. Explicit knowledge codification ensured the aggregated explicit knowledge was comprehensive, of high quality, and ready to be transferred. Explicit knowledge impartation aimed at exposing the offshore members to as much as explicit knowledge and providing them with the opportunity to get access to the knowledge. Second, only when the explicit knowledge was sufficiently acquired by offshore members could the onshore teams start to deliver tacit knowledge. By evaluating the knowledge acquisition, onshore managers could check whether the explicit knowledge delivered in the common lexicon was sufficiently acquired by offshore members. This could help onshore managers to control and improve the acquisition process and decide whether to start delivering tacit knowledge. Oral and written quizzes were used to evaluate this acquisition progress.

\section{Translating Across Semantic Boundary}

The translation of knowledge across semantic boundary also requires two preconditions: (1) creating a common meaning between onshore and offshore teams, and (2) assimilating sufficient tacit knowledge from onshore teams by offshore teams. Firstly, cross-team interaction and interpretation, facilitated by on-job-training (OJT) and Playback sessions, had created a common meaning between onshore and offshore teams. During these processes, onshore and offshore members exchanged and coordinated their interpretations and created a common meaning of the tacit knowledge. Second, only when the tacit knowledge was sufficiently assimilated by offshore members could the offshore members start to apply the knowledge. By evaluating knowledge assimilation, onshore managers could check whether the tacit knowledge delivered via the common meaning was sufficiently assimilated by offshore members. This could help onshore managers to control and improve the assimilation process and decide whether the offshore members were eligible to apply the knowledge. The individual interview assessment and team review were used to evaluate the assimilation results.

\section{Transforming Across Pragmatic Boundary}

The transformation of knowledge across pragmatic boundary also requires two conditions: (1) creating a common interest between onshore and offshore teams, and (2) applying sufficient knowledge to real work by offshore teams. Firstly, BankCo had created a common interest between onshore and offshore teams by prototyping and interest negotiation. Though the support simulation, offshore members could learn the solutions for some past problems without injuring anyone's interest. What they did was mainly situating themselves in past problematic conditions and trying to learn from onshore members' experience and solutions. This is regarded as marginally win-win situation. Interest negotiation was facilitated by the audit by Quality Managers as well as the team readiness assessment by onshore and offshore managers. 
Delivering Knowledge Across Boundaries: A Case Study of Bankco's Offshoring Projects / Feng et al.

Through these processes, onshore and offshore stakeholders jointly checked the readiness of the offshore members and decided whether the jobs could be independently handled by offshore teams. Onshore and offshore members negotiated and parallelized their interests for the jobs and created a common interest for the applicability of knowledge by offshore members. Second, only when the knowledge was sufficiently applied by offshore members into real work could the offshore sourcing project be re- garded as a success.

In sum, this study made a distinction among the three phases of knowledge delivery and integrated different mechanisms as boundary objects supporting the creation of common knowledge across the three temporal phases and proposed a framework of the underlying processes through which knowledge delivered from onshore teams to offshore teams can be inductively derived (refer to the circle in Figure 3).

\section{Table 2 - Knowledge Delivery and Boundary Objects Building}

\begin{tabular}{|c|c|c|}
\hline $\begin{array}{l}\text { Delivery } \\
\text { Phase }\end{array}$ & $\begin{array}{c}\text { Boundary Object } \\
\text { Building }\end{array}$ & Activities Conducted by BankCo \\
\hline \multirow[t]{2}{*}{$\begin{array}{c}\text { Transferring } \\
\text { Phase }\end{array}$} & $\begin{array}{l}\text { Creating common } \\
\text { lexicon }\end{array}$ & $\begin{array}{l}\text { By recruiting qualified staffs from offshore location, } \\
\text { BankCo's offshore project managers built up expertise off- } \\
\text { shore teams } \\
\text { By preparing transition guide, BankCo's onshore teams initi- } \\
\text { ated the offshoring project } \\
\text { By pulling knowledge from distributed locations and experts, } \\
\text { BankCo centralized the knowledge of onshore teams for de- } \\
\text { livery } \\
\text { By documenting and codifying the explicit knowledge into } \\
\text { manuals and presentation slides, BankCo is well prepared } \\
\text { for explicit knowledge transfer. } \\
\text { By holding face-to-face, one-to-many presentations, } \\
\text { BankCo's onshore teams imparted their explicit knowledge } \\
\text { to offshore members }\end{array}$ \\
\hline & $\begin{array}{l}\text { Acquiring explicit } \\
\text { knowledge }\end{array}$ & $\begin{array}{l}\text { By oral and written quizzes, BankCo's onshore teams eval- } \\
\text { uated the amount of explicit knowledge acquired by offshore } \\
\text { teams }\end{array}$ \\
\hline \multirow[t]{2}{*}{$\begin{array}{l}\text { Translating } \\
\text { Phase }\end{array}$} & $\begin{array}{l}\text { Creating common } \\
\text { meaning }\end{array}$ & $\begin{array}{l}\text { - By sending onshore members to do On-Job-Training at off- } \\
\text { shore sites, BankCo facilitated the cross-team interactions } \\
\text { By allowing onshore teams to observe and correct offshore } \\
\text { members' work in the Playback sessions, BankCo facilitated } \\
\text { the exchange of tacit knowledge between two teams and } \\
\text { enabled vendors to form a better interpretation of the project }\end{array}$ \\
\hline & $\begin{array}{l}\text { Assimilating tacit } \\
\text { knowledge }\end{array}$ & $\begin{array}{l}\text { By conducting individual interview assessment and team } \\
\text { reviews, BankCo's onshore teams evaluated the amount of } \\
\text { tacit knowledge assimilated by offshore teams }\end{array}$ \\
\hline \multirow[t]{2}{*}{$\begin{array}{c}\text { Transforming } \\
\text { Phase }\end{array}$} & $\begin{array}{c}\text { Creating common } \\
\text { interest }\end{array}$ & $\begin{array}{l}\text { By teaching offshore teams to solve the past problems, } \\
\text { BankCo prototyped the former knowledge and enhanced } \\
\text { offshore teams' application capability without injuring any- } \\
\text { one's interest } \\
\text { By auditing the Team Transition Process by Quality Manag- } \\
\text { ers and jointly measuring the readiness of offshore teams by } \\
\text { onshore and offshore managers, BankCo negotiated the in- } \\
\text { terests among various stakeholders and achieved shared in- } \\
\text { terests }\end{array}$ \\
\hline & $\begin{array}{l}\text { Applying delivered } \\
\text { knowledge }\end{array}$ & $\begin{array}{l}\text { By allowing offshore teams to work together with onshore } \\
\text { teams and apply the knowledge they had learnt in real pro- } \\
\text { duction work, BankCo reaped the most benefits of offshoring } \\
\text { project }\end{array}$ \\
\hline
\end{tabular}




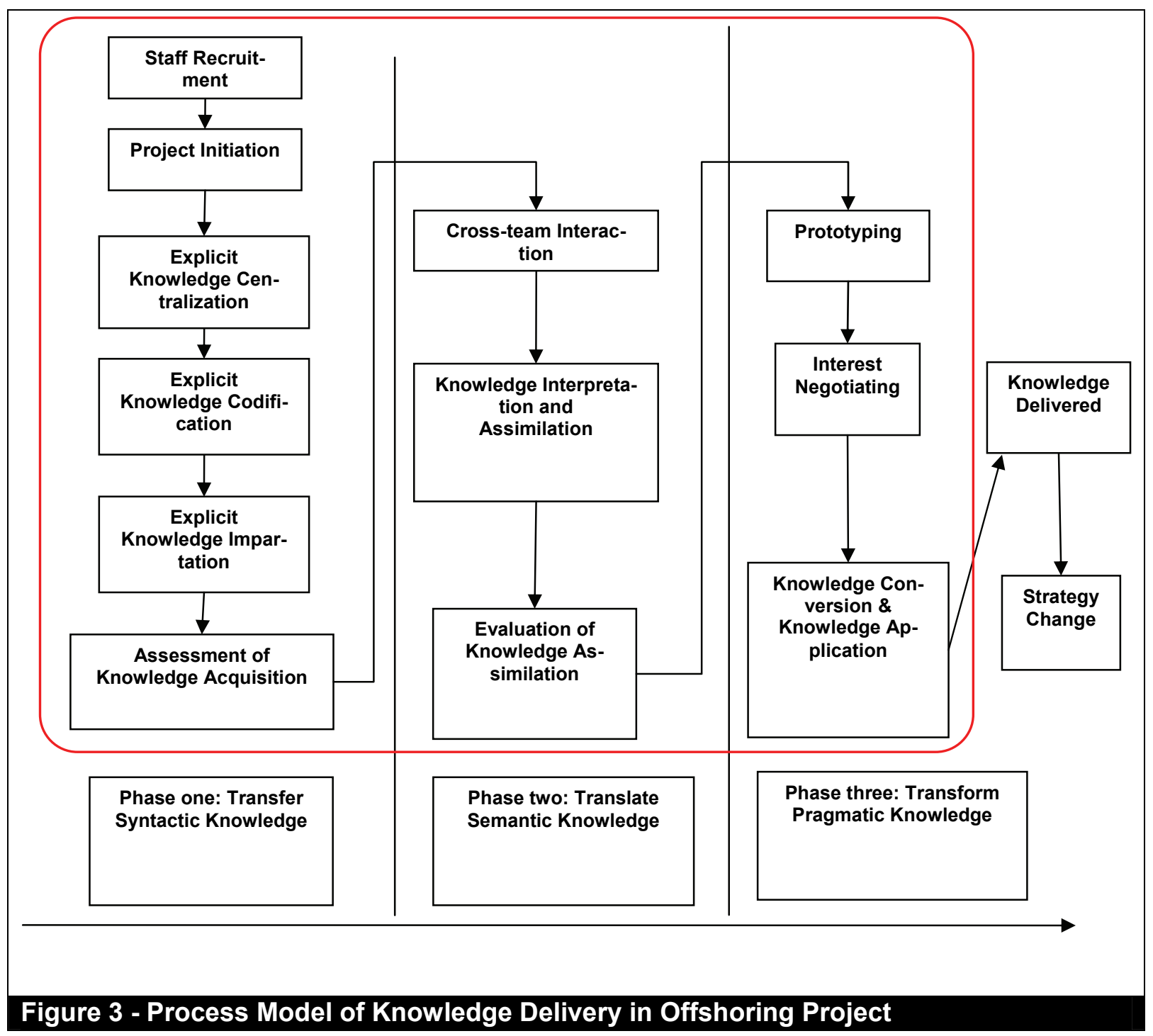

Barriers for Knowledge Delivery and Their Influences on Offshore Sourcing Strategy

\section{Heterogeneous Understanding}

From the process framework above, we can see that knowledge is delivered with the help of boundary objects through the transferring, translating and transforming processes. In the translating process, common meanings are established between two parties when knowledge is not easily described or understood by the original understanding. In this process, knowledge is of highly practiceembedded and sticky to the practice and employees who hold them, which requires off- shore team members to spend more time and efforts to assimilate the interpretive knowledge in this process than syntactic knowledge in the transfer process. The effectiveness of establishing the common meaning directly affects the amount of interpretive knowledge assimilated by offshore team members in this process. From the case, onthe-job training is one of the methods to establish common meaning and translate some knowledge into the daily knowledge for the offshore members to pick up them easily and demonstrate some practices. After this process, most of the interpretive knowledge is translated and properly assimilated by the offshore team members. 
Delivering Knowledge Across Boundaries: A Case Study of Bankco's Offshoring Projects / Feng et al.

\section{Conflicting Interest}

In the transforming process, onshore and offshore teams are endeavoring to establish common interest to deliver more competitive knowledge from onshore members to offshore members. The pragmatic knowledge delivered is a type of competitive knowledge that employees gain from the daily working and practices. Offshore members have to replace their competitive knowledge with the onshore members' knowledge, which costs them more time and efforts to master those types of knowledge and make sure the newly absorbed knowledge is enough to handle their jobs. Although the simulation process prototypes the real business routines, offshore members have difficulty in transforming the knowledge for their own use. They are not likely to convert knowledge they learned and put the new knowledge into application for the sake of either its path dependence or in the sense that they are not willing to discard their hard-won skills. Besides, pragmatic knowledge is embedded in clients' experience and practices, thereby not easy to be transformed, converted and applied into practice for offshore members.

On the other side, the onshore team members are not willing to impart their unique knowledge to offshore team members who will be laid off after the project, because doing so will jeopardize their strategic advantages. In order to keep their own advantages, the onshore team members will hoard certain knowledge (Wasko and Faraj, 2005). In the offshore teams, the lack of motivations to spend time in converting and applying new knowledge into work makes the knowledge hoarding problem much worse, thereby reducing vendors' work efficiency and jeopardizing their performance level.

In conclusion, the delivered pragmatic knowledge is insufficient and the absorptive capacity of offshore team members is not high enough to transform pragmatic knowledge for their own use. In the end, BankCo realized that the knowledge of the system analysts and programmers could be replicated in the offshore locations. However, the more senior analysts and project managers possessed application domain knowledge, which were not easily transferred to the offshore staffs. The intention of replicating or "outsourcing" the whole onshore team capability into an offshore team did not seem viable. Therefore, the BankCo's managers changed their original strategy as a result of the fact that the amount of pragmatic knowledge absorbed by the offshore teams is not enough for them to independently operate the routines that are previously conducted by the onshore teams. By integrating both the remaining senior members of the onshore teams with the offshore teams into one cohesive team - one global team with members in different geographic locations, reporting into one manager, BankCo successfully facilitated the knowledge delivery. This enabled the onshore and offshore teams to work together, share knowledge and experiences, and solve problems together as one. Onshore team members with highly pragmatic knowledge do not have to be laid off so that offshore team members have more time to absorb and transform the skills taught by onshore team members for their own use.

\section{Conclusion}

Knowledge delivery is challenging but crucial for companies sourcing their work from offshore locations, especially in current economic depression time when companies are facing cost pressures on their bottom line. As the list of companies moving their operations to offshore cheap labour cost locations continues to expend, delivering concise and necessary business knowledge from onshore to offshore locations has become an urgent agenda for onshore managers and executives. To address the knowledge gap, this research elucidates the actual process of knowledge delivery and boundary objects, providing richer insights and more effective knowledge delivering mechanisms for offshoring exploitations. We conclude this paper by discussing the major contributions and limitations as well as proposing some of the future research directions. 
Delivering Knowledge Across Boundaries: A Case Study of Bankco's Offshoring Projects / Feng et al.

\section{Theoretical Contribution}

By providing a systematic process analysis of offshore knowledge delivery, this article contributes to the academic literature in several ways. First, by constructing a model of the process of knowledge delivery in offshoring project, this study fills an important gap in the literature. As it is important to consider the specific nature of knowledge delivery and processes imposed upon (Hansen, 1999) by the organization in each instance of knowledge delivery, the generic Critical Success Factors and key mechanisms (e.g., Hansen, 1999; Ko et al., 2005) prescribed for knowledge delivery may be less relevant or useful than understanding the actual process through which organizational employees interpret and explain information from and negotiate with the clients that leads to the enlistment of the appropriate action (Dibern et al., 2008). This study sheds a light on the mechanisms enabling the vendors to understand and act upon the specific issues of knowledge boundary within and surrounding the process of knowledge delivery, contributing a different perspective of effective knowledge delivery that accounts for its complex and idiosyncratic nature.

Second, this article proposes an integrative framework by combining the knowledge boundary framework and absorptive capacity theory. By doing so, this article extends the original knowledge boundary framework by discussing efficiency issues of knowledge delivery (Carlile, 2002, 2004) and explaining the success of knowledge delivery in the presence of appropriate boundary objects and high absorptive capacity of receivers.

Third, this study has identified three different approaches (i.e., transfer, translate, transform) to knowledge delivery that stem from three distinct boundary objects (i.e., common lexicon, common meaning, common interest). In establishing the intricate connectedness between the three processes, this study makes an important contribution to knowledge delivery research as it demonstrates that knowledge delivery is not a singular, homogenous process as is typically assumed in the literature (e.g., Hansen, 1999), but rather constituted by a set of heterogeneous processes. In addition, the three distinct approaches, when taken together, form an empirically grounded typology of knowledge delivery processes that future research can build upon. In particular, future studies can examine the nature of the three knowledge delivery approaches identified, or investigate other antecedents or consequences of the different approaches that are beyond the scope of the current study.

Fourth, this study has identified the importance of boundary objects in delivering knowledge from one party to another. By identifying several complementary boundary objects, this study contributes to the knowledge delivery research by providing another strategy of keeping knowledge from spilling-over to competitors (i.e., hiding the boundary objects from the competitors). In combination with the organizational structure, future study can investigate the influence of boundary objects in organizational knowledge delivery and organizational innovation.

Finally, this study also contributes to the literature on absorptive capacity. Although recent absorptive capacity research has made a conceptual distinction between the different elements of absorptive capacity (e.g. Zahra and Geogre, 2002), little attention has been paid to how knowledge boundary objects affect absorptive capacity. The process model developed in this article is thus an important contribution, as it underscores the importance of boundary objects as the premise of absorptive capacity.

\section{Practical Contribution}

Practically, this article provides a comprehensive and strong explanation for knowledge delivery in the offshore sourcing process. First, it renders inspiration for the creation of new and useful knowledge delivering mechanisms for the offshore sourcing project. For the practitioners who are involved in offshoring projects, this study suggests that establishing connections, translating possible terminologies, and negotiating the willingness of collaborations are important activities that 
Delivering Knowledge Across Boundaries: A Case Study of Bankco's Offshoring Projects / Feng et al.

should be done before they initiate the actual and massive offshore delivery. During the knowledge delivery process, practitioners should actively acquire, assimilate, and convert the clients' knowledge.

Second, it provides strategies to facilitate inter-organizational knowledge delivery and prevent some kind of knowledge from leaking to competitors. Organizations can train all their employees the set of shared codes and norms in promoting the knowledge delivery within the whole organization. Also, this study suggests that as long as organizations hide the knowledge boundary objects, competitors cannot pick up the knowledge easily and imitate the technologies that these organizations are using or offshoring.

\section{Limitation and Future Study}

This article demonstrates at a deeper level why communication across offshore sourcing participations is hard and how different types of knowledge are delivered, based on the knowledge boundary framework and absorptive capacity. The data of this study is collected by qualitative case study method which has been criticized as lacking of statistically generalizability or external validity (Walsham, 2006). However, we cannot assert that our study is valid and generalizable beyond its context. The developed process model is grounded in the interpretation of a real world

\section{References}

Aron, R. and Singh, J. V. (2005). Getting Offshoring Right, Harvard Business Review, 83(2), 135-140.

Beugre, C.D. and Acar, W. (2008). "Offshoring and Cross-Border Interorganizational Relationships: A Justice Model," Decision Sciences, 39(3), 445-468.

Brown, J. S. and P. Duguid. (2001). "Knowledge and organization: A social practice perspective," Organization Science, 12(2), 198-213.

Caloghirou, Y. I., Kastelli. A., and Tsakanikas A. (2004). "Internal capabilities and external knowledge sources: complements or substitutes for innovative offshoring project, as well as corroborated by the propositions of some of the most established works in management and IS literature (e.g., Carlile, 2002, 2004; Ko et al., 2005). As such, this study conforms to the principles of "analytic generalization" (Yin, 2003). Nevertheless, future research can be directed at statistically validating the concepts involved in our process model, so that the boundary conditions of our study can be better defined.

A second limitation of this study concerns with the retrospective nature of the personal interviews that form our primary source of data. Retrospective responses are susceptible to errors of recall (Glick et al., 1990). In order to reduce the errors of recall, we have tried to circumscribe the problem by only having informants who were personally involved in the offshoring project during the relevant period of interest. In addition, a systematic data verification procedure was adopted to ensure that all the information used in this study was triangulated by at least two sources of data from the vendor and the client (Klein and Myers, 1999). However, future research applying findings of this study to other cases or contexts could yield more reliable insights by referring to additional sources of data such as company financial reports, annual reports, field survey, or market reports from third parties.

performance," Technovation, 24(1), 29-39.

Carlile, P.R. (2002). "A pragmatic view of knowledge and boundaries: boundary objects in new product development," Organization science, 13(4), 442-455.

Carlile, P.R. (2004). "Transferring, Translating, and Transforming: An Integrative Framework for Managing Knowledge across Boundaries," Organization science, 15(5), 555-568.

Carlile, P. and Rebentisch, E. (2003). "Into the black box: The knowledge transformation cycle," Management Science, 49(9),1180-1195. 
Delivering Knowledge Across Boundaries: A Case Study of Bankco's Offshoring Projects / Feng et al.

Carmel, E. and Agarwal, R. (2002). "The maturation of offshore sourcing of information technology work," MIS Quarterly Executive, 1(2), 65-77.

Chen, J. and McQueen, R. J. (2010). "Knowledge Transfer Processes for Different Experience Levels of Knowledge Recipients at an Offshore Technical Support Center," Information Technology \& People, 23(1), 54-79.

Chua, A. L. and Pan, S. L. (2008). "Knowledge transfer and organizational learning in IS offshore sourcing," Omega- the International Journal of Management Science, 36(2), 267281.

Cohen, W. M. and Levinthal, D. A. (1990). "Absorptive Capacity: A New Perspective on Learning and Innovation," Administrative Science Quarterly, 35(1), 128-152

Cummings, J. N. (2004). "Work groups, structural diversity, and knowledge sharing in a global organization," Management Science, 50(3), 352-364.

Dibbern, J., Winkler, J., and Heinzl, A. (2008). "Explaining Variations in Client Extra Costs between Software Projects Offshored to India," MIS Quarterly, 32(2), 333-366.

Escribano, A., Fosfuri, A., and Tribo, J. A. (2009). "Managing External Knowledge Flows: The Moderating Role of Absorptive Capacity," Research Policy 38(1), 96-105

Everest Group Research Institute. (2009). http://cwstage.live.rss-hosting.co.uk/ files/239834/FileName/EnterpriseMauritius-LeveragingITtoExportBusi nessServices(8June2011).pdf

Ferlie, E., Fitzgerald, L., Wood, M., and Hawkins, C. (2005). "The nonspread of innovations: The mediating role of professionals," Academy of Management Journal, 48(1), 117-134.
Galbraith, C. S. (1990). "Transferring Core Manufacturing Technologies in High Technology Firms", California Management Review, 32(4), 56-70.

Glick, W.H., Huber, G.P., Miller, C.C., Doty, D.H., and Sutcliffe, K.M. (1990). "Studying changes in organizational design and effectiveness: Retrospective event histories and periodic assessments " Organization Science 1(3), 293-312.

Global Services Media. (2010). http://siteresources.worldbank.org/INT PREMNET/Resources/EP35.pdf

Gottschalk, P. and Solli-Sather, H. (2007). "Knowledge Transfer in IT Outsourcing Relationships: Three International Case Studies," International Journal of Innovation and Learning, 4(2), 103111.

Gupta, A. and Govindarajan, V. (2000). "Knowledge flows within multinational corporations," Strategic Management Journal , 21(4), 473-496.

Hamel, G. (1991). "Competition for Competence and Inter-partner Learning Within International Strategic Alliances," Strategic management Journal (12), 83-103.

Hansen, M. T. (1999). "The Search-Transfer Problem: The Role of Weak Ties in Sharing Knowledge across Organizational Subunit," Administrative Science Quarterly, 44(1), 82-111.

Helfat, C. E. (1994). "Firm-specificity in Corporate R\&D," Organization Science, 5(2), 173-184

Kearney, A.T. (2007). "Offshoring for Longterm Advantage," The 2007 A.T. Kearney Global Services Location Index, A.T. Kearney.

Klein, H. K. and Myers, M. D. (1999). "A set of principles for conducting and evaluating interpretive field studies in information systems," MIS Quarterly, 23(1), 67-93. 
Delivering Knowledge Across Boundaries: A Case Study of Bankco's Offshoring Projects / Feng et al.

Ko, D. G., Kirsch, L. J., and King, W. R. (2005). "Antecedents of knowledge transfer from consultants to clients in enterprise system implementations," MIS Quarterly, 29(1), 144-170.

Lane, P. J., Salk, J. E., and Lyles, M. A. (2001). "Absorptive Capacity, Learning, and Performance in International Joint Ventures," Strategic Management Journal, 22(12), 1139-1161.

Lee, J-N. (2001). "The impact of knowledge sharing, organizational capability and partnership quality on IS outsourcing success," Information \& Management 38(5), 323-335.

Levina, N. and Vaast, E. (2008). "Innovating or Doing as Told? Status Differences and Overlapping Boundaries in Offshore Collaboration," MIS Quarterly 32(2), 307-332.

Li, Y., Wei, Z. and Liu, Y. (2010). "Strategic Orientations, Knowledge Acquisition, and Firm Performance: The Perspective of the Vendor in Cross-Border Outsourcing," Journal of Management Studies, 47(8), 1457-1482.

Miller, D. and Shamsie, J. (1996). "The Resource-Based View of the Firm in Two Environments: The Hollywood Film Studios from 1936 to 1965," Academy of Management Journal, 39(3), 519543.

Modi, S. and Malbert, V. (2007). "Supplier development: improving supplier performance through knowledge transfer," Journal of Operations Management, 25(1), 42-64.

Mowery, D. C. (1983). "The Relationship between Intrafirm and Contractual Forms of Industrial Research in American manufacturing, 1900-1940," Explorations Economics History, 20(4), 351-374.

Oshri, I., Pan, S-L, and Newell, S. (2006). "Managing Trade-Offs and Tensions between Knowledge Management Initiatives and Expertise Development
Practices," Management Learning, 37(1), 63-82.

Pan, S-L and Leidner, D. (2003). "Bridging Communities of Practice with Information Technology in Pursuit of Global Knowledge Sharing," Journal of Strategic Information Systems,12(1), 71-88.

Pan, S-L, Pan, G., Chen, J. W., and Hsieh, $\mathrm{M}-\mathrm{H}$. (2007). "The Dynamics of Implementing and Managing Modularity of Organizational Routines during Capability Development: Insights from a Process Model," IEEE Transactions of Engineering Management, 54(4), 800813.

Pan, S-L and Scarbrough, H. (2006). "Knowledge Management in Practice: An Exploratory Case Study of Buckman Labs," Technology Analysis and Strategic Management, 11(3), 359374.

Pan, S-L and Tan, B. (2011). "Demystifying Case Research: A StructuredPragmatic-Situational (SPS) Approach to Conducting Case Studies," Information and Organization, 21(3), 161176.

Park, J. Y., Im, K. S., and Kim, J. S. (2011). "The Role of IT Human Capability in the Knowledge Transfer Process in IT Outsourcing Context," Information \& Management, 48(1), 53-61.

Rothaermel F. T. and Alexanfre, M. T. (2009). "Ambidexterity in Technology Sourcing: The Moderating Role of Absorptive Capacity," Organization Science 20(4), 759-780.

Sri Lanka's National Newspapers. (2011). http://www.dailynews.lk/2011/07/15/bu s06.asp

Szulanski, G. (1996). "Exploring internal stickiness: Impediments to the transfer of best practice with the firm," Strategic Management Journal, 17(4), 27-43. 
Delivering Knowledge Across Boundaries: A Case Study of Bankco's Offshoring Projects / Feng et al.

Tan, C. W., Pan, S. L., Lim, E. T. K., and Chan, C. M. L. (2005). "Managing Knowledge Conflicts in an InterOrganizational Project: A Case Study of IDA Singapore," Journal of the American Society for Information Systems and Technology, 56(11), 11871199.

Teece, D. J. (2000). Managing Intellectual Capital, Oxford University Press, Oxford, England.

Thatcher, M. E., Cha, H. S., Ahuja, M. K., and Pingry, D. E. (2011). "IT Outsourcing: Assessing the Antecedents and Impacts of Knowledge Integration,", Proceedings of $44^{\text {th }}$ Hawaii International Conference on System Sciences.

Vlaar, P., Fenema, P., and Tiwari, V. (2008). "Co-Creating Understanding and Value in Distributed Work: How Members of Onsite and Offshore ISD Vendor Teams Give, Make, Demand and Break Sense," MIS Quarterly, 32(2), 227-255.

Von Krogh, G., Ichijo, K., and Nonaka, I. (2000). Enabling Knowledge Creation, Oxford University Press, Oxford, England.

\section{About Authors}

Yuanyue Feng is currently a $\mathrm{PhD}$ candidate in Department of Information Systems at $\mathrm{Na}$ tional University of Singapore. He holds a bachelor degree in Management Information Systems from Renmin University of China, China. His research interests cover the global outsourcing, project management, entrepreneurship, and knowledge sharing in online communities. His work has been published in International Conference on Information Systems (ICIS) and Pacific Asia Conference on Information Systems (PACIS).
Walsham, G. (2006). "Doing interpretive research," European Journal of Information Systems, 15(3), 320-330.

Wasko, M. M. and Faraj, S. (2005). "Why should I share? Examining social capital and knowledge contribution in electronic networks of practice," MIS Quarterly, 29(1), 35-57.

Williams, C. (2011). "Client-vendor Knowledge Transfer in IS Offshore Outsourcing: Insights from a Survey of India Software Engineers," Information Systems Journal, 21(4), 335356.

Willcocks, L., Feeny, D., and Lacity, M. (2004). "IT and business process outsourcing: the knowledge potential," Information Systems Management, 21(3), 7-15.

Yin, R. K. (1994). Case study research: design and methods, Beverley Hills, CA: Sage Publications Inc.

Yin, R. K. (2003). Case Study Research: Design and Methods, (3rd ed.) Sage, Thousand Oaks, CA.

Zahra, S. and George, G. (2002). "Absorptive capacity: A review, reconceptualization, and extension," Academy of Management Review, 27(2), 185-203.

Hua Ye is currently a PhD candidate in Department of Information Systems at National University of Singapore. He holds a bachelor degree in Electronic Commerce from Huazhong Normal University, China. His research interest lies in the open innovation, service innovation, and knowledge sharing in online communities. His work has been published in International Conference on Information Systems (ICIS), Academy of Management Annual Meeting (AOM), European Conference on Information Systems (ECIS), and Pacific Asia Conference on Information Systems (PACIS). 
Shan L. Pan is an Associate Professor of Information Systems and the Academic Director of the Strategic Technology Management Institute at the National University of Singapore (NUS). His research work has been published in various top tier academic and practitioner journals such as Information
Systems Research, MISQ Executive; IEEE Transactions on Systems, Man, and Cybernetics; IEEE Transactions on Engineering Management; IEEE Transactions on IT in Biomedicine; and the Journal of the American Society for Information Systems and Technology. 